\title{
NOVEL DOUBLE ROLLER BEARING FE ANALYSIS AND COMPARISON WITH CONVENTIONAL DOUBLE ROW CYLINDRICAL ROLLER BEARING
}

\author{
Mr. Anand kalani \\ Mechanical Engineering Department, \\ Government Engineering College Palanpur, India \\ Mrs. Rita jani \\ Mechanical Engineering Department, \\ Shantilal Shah Engineering College, Bhavnagar, India
}

\begin{abstract}
When for a given shaft diameter the load is beyond the load carrying capacity of a ball bearing or shock loading or there is a possibility of severe unknown loads, then a roller bearing has to be considered. The load carrying capacity of a single row roller bearing is less than that of a double row roller bearing. But the double row roller bearing requires more housing space. But the double row roller bearing requires more housing space. The design of novel bearing can replace angular contact deep groove ball bearing and double row cylindrical roller bearing. This new type of bearing can take high radial load as well as axial load.
\end{abstract}

Key words: Contact Pressure, Contact Stress, Double Row Roller, Hertzian Stress, Novel Bearing.

Cite this Article: Mr. Anand Kalani and Mrs. Rita Jani, Novel Double Roller Bearing $\mathrm{Fe}$ Analysis and Comparison with Conventional Double Row Cylindrical Roller Bearing. International Journal of Design and Manufacturing Technology 6(2), 2015, pp. 29-39. https://iaeme.com/Home/issue/IJDMT?Volume $=6 \&$ Issue $=2$

\section{INTRODUCTION}

A bearing is a device to allow constrained, smooth, low-friction movement between two or more surfaces. The terms rolling-contact bearing, antifriction bearing, and rolling bearing are all used to describe that class of bearing in which the main load is transferred through elements in rolling contact rather than in sliding contact. There are many types of bearings, each used for different purposes. These include ball bearings, 
roller bearings, ball thrust bearings, roller thrust bearings and tapered roller thrust bearings.

\section{CYLINDRICAL ROLLER BEARING}

In the various types of cylindrical roller bearings, the rollers are guided on one of the two rings between fixed lips, and linked by the cage to form a unit with this ring, this contributes to the rigidity of the bearing and a precise radial guidance of the shaft. For special applications, full-complement cylindrical roller bearings are employed. The cylindrical roller bearing designs are shown in Figure 1.

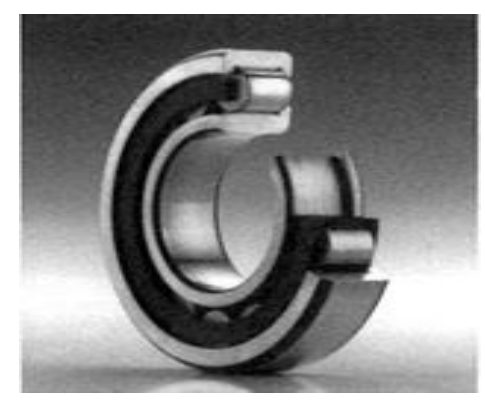

Figure 1 Double Row Cylindrical Bearing

The designs of cylindrical roller bearings are distinguished by the arrangement of the lips. Design NU (Figure 2b) has two lips on the outer ring, the inner ring being lipless. In design $\mathrm{N}$ (Figure 2a), the inner ring has two lips, the outer ring has none. Cylindrical roller bearings of designs $\mathrm{NU}$ and $\mathrm{N}$ are applied as floating bearings because the rollers can freely shift on the lipless ring in the axial direction. Cylindrical roller bearings NJ (Figure 2d) have two lips on the outer ring and one on the inner ring; they can take up axial forces in one direction. Design NUP (Figure 2c) is installed as a locating bearing to sustain frequently reversing axial forces. This bearing has two lips on the outer ring, a fixed lip and a loose lip on the inner ring. A cylindrical roller bearing NJ with an angle ring HJ (Figure 2d) forms a locating bearing similar to design NUP.Cylindrical roller bearings of current series are mainly produced with internal redesign giving higher capacity. These bearings, designated by the suffix $\mathrm{E}$, have the same outer dimensions as the bearings without suffix E, but the rollers have a larger diameter and length, which considerably increases the load-carrying capacity.

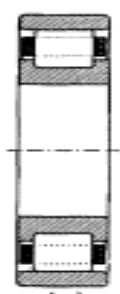

(a)

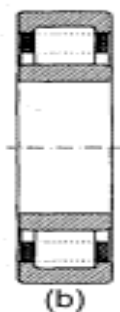

(b)

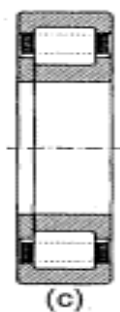

(c)

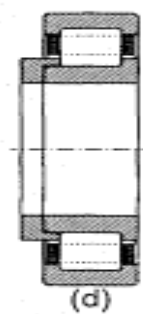

(d)

Figure 2 Cylindrical roller bearings:

(a) Design N(b) design NU(c) design NUP (d) design NJ with angle ring 


\section{HERTZIAN CONTACT STRESSES [1]}

When two bodies having curved surfaces are pressed together, point or line contact changes to area contact, and the stresses developed in the two bodies are three dimensional. The most general case of contact stress occurs when each contacting body has a double radius of curvature; that is, when the radius in the plane of rolling is different from the radius in a perpendicular plane, both planes taken through the axis of the contacting force. Here we shall consider only the two special cases of contacting spheres and contacting cylinders. The results presented here are due to Hertz and so are frequently known as Hertzian stresses.

\subsection{Cylindrical Contact}

Figure $3 a$, illustrates a similar situation in which the contacting elements are two cylinders of length $l$ and diameters $d 1$ and $d 2$. As shown in Figure 13b, the area of contact is a narrow rectangle of width $2 b$ and length $l$, and the pressure distribution is elliptical. The half-width $b$ is given by the equation

$$
b=\sqrt{\frac{2 F}{\pi l} \frac{\left(1-v_{1}^{2}\right) / E_{1}+\left(1-v_{2}^{2}\right) / E_{2}}{1 / d_{1}+1 / d_{2}}}
$$

The maximum pressure is

$$
p_{\max }=\frac{2 F}{\pi b l}
$$

Equation $1 \&$ Equation 2 apply to a cylinder and a plane surface, such as a rail, by making $d=\infty$ for the plane surface. The equations also apply to the contact of a cylinder and an internal cylindrical surface; in this case $d$ is made negative for the internal surface.

The stress state along the $z$ axis is given by the equations

$$
\begin{aligned}
& \sigma_{x}=-2 v p_{\max }\left(\sqrt{1+\frac{z^{2}}{b^{2}}}-\left|\frac{z}{b}\right|\right) \\
& \sigma_{y}=-p_{\max }\left(\frac{1+2 \frac{z^{2}}{b^{2}}}{\sqrt{1+\frac{z^{2}}{b^{2}}}}-2\left|\frac{z}{b}\right|\right) \\
& \sigma_{3}=\sigma_{z}=\frac{-p_{\max }}{\sqrt{1+z^{2} / b^{2}}}
\end{aligned}
$$

For $0 \leq z \leq 0.436 b, \sigma_{1}=\sigma_{x}$, and $\tau_{\max }=\left(\sigma_{1}-\sigma_{3}\right) / 2=\left(\sigma_{x}-\sigma_{z}\right) / 2$. For $z \geq 0.436 b, \sigma_{1}=\sigma_{y}$, and $\tau_{\max }=\left(\sigma_{y}-\sigma_{z}\right) / 2$. A plot of $\tau_{\max }$ is also included in Fig.14, where the greatest value occurs at $z / b=0.786$ with a value of $0.300 p_{\max }$. 

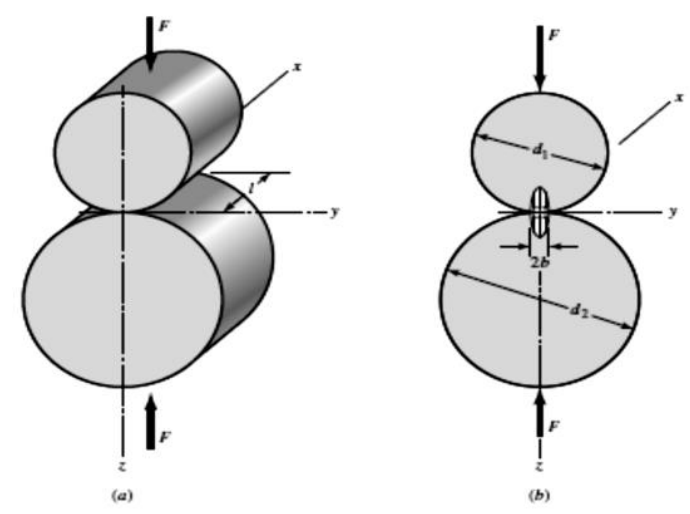

Figure 3 (a) Two right circular cylinders held in contact by forces $\mathrm{F}$ uniformly distributed along cylinder length 1. (b) Contact stress has an elliptical distribution across the contact zone width $2 b$.

\section{UMERICAL ANALYSES}

\subsection{Analysis of Single Roller of a double row cylindrical Bearing [2]}

The value of $\mathrm{F}=2500 \mathrm{~N}$ which is half of the total load of bearing i.e. $5000 \mathrm{~N}$, reason for taking value of $2500 \mathrm{~N}$ is the arrangement of the roller in double row bearing which is as shown in Figure 4.

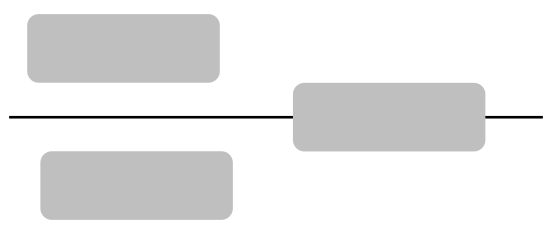

Figure 4 Arrangement of rollers

The single roller of the bearing designation / for the ease of calculation single roller is taken under consideration and diameter of the roller is converted into equivalent diameter.

Equivalent Diameter 'D'

$\frac{1}{D}=\frac{1}{D 1}+\frac{1}{D 2}=\frac{1}{8}+\frac{1}{60}=0.14167$

$D=7.05865 \approx 7.059$

Calculation for finding contact width ' $b$ '

$$
b=\sqrt{\frac{2 F}{\pi l} \frac{\frac{1-\vartheta_{1}^{2}}{E_{1}}+\left(1-\vartheta_{2}^{2}\right) / E_{2}}{\frac{1}{D_{1}}+\frac{1}{D_{2}}}}=\sqrt{\frac{2 * 2500}{\pi * 8} \frac{\frac{1-0.277^{2}}{2.0133 * 10^{5}}+\frac{1-0.277^{2}}{2.0133 * 10^{5}}}{0.14167}}
$$

$\mathrm{b}=\mathbf{0 . 1 1 3 4 8 8 4} \approx \mathbf{0 . 1 1 3 5}$ 
Calculation for ' $p_{\max }$ '

$p_{\max }=\frac{2 F}{\pi b l}=\frac{2 * 2500}{\pi * 0.1135 * 8} \quad \mathbf{p}_{\max }=\mathbf{1 7 5 2 . 8 0 7 7 4 3} \approx \mathbf{1 7 5 2 . 8 0 8}$

Calculation for pressure ' $p$ '

$P=\frac{F}{A}=\frac{2500}{7.059 * 8}=\mathbf{4 4 . 2 6 9 7 2 6 5 9} \approx \mathbf{4 4 . 2 7 0}$

Von-Mises stress

$$
\sigma_{v m}=\sqrt{\frac{1}{2}\left[\left(\sigma_{x}-\sigma_{y}\right)^{2}+\left(\sigma_{y}-\sigma_{z}\right)^{2}+\left(\sigma_{z}-\sigma_{x}\right)^{2}\right]}
$$

Where,

$$
\begin{gathered}
\boldsymbol{\sigma}_{\boldsymbol{x}}=-2 * \mu * p_{\max }=-2 * 0.277 * 1752.808=-\mathbf{9 7 1 . 0 5 6} \\
\boldsymbol{\sigma}_{\boldsymbol{y}}=\boldsymbol{\sigma}_{\boldsymbol{z}}=\boldsymbol{p}_{\max }=-\mathbf{1 7 5 2 . 8 0 8} \\
\sigma_{v m} \\
=\sqrt{\frac{1}{2}\left[((-971.056)-(-1752.808))^{2}+((-1752.808)-(-1752.808))^{2}+((-1752.808)-(-971.056))^{2}\right]} \\
\sigma_{v m}=\sqrt{\frac{1}{2}[611136.1895+0+611136.1895]} \\
\boldsymbol{\sigma}_{v \boldsymbol{m}}=\mathbf{7 8 1 . 7 5 2}
\end{gathered}
$$

\subsection{Analysis of Novel Roller Bearing}

$P=\frac{F}{A}=\frac{5000}{[(7.059 * 8)+(3.5295 * 3)+(7.059 * 8)]}=\mathbf{4 0 . 7 4 2 3 2 5 1 6} \approx \mathbf{4 0 . 4 7 2}$

\section{FINITE ELEMENT ANALYSIS}

\subsection{Finite Element Analysis of Double Row Cylindrical Bearing}

For the purpose of analysis single roller of in double row bearing is the arrangement of the rollers in the double row bearing as shown in fig.

\section{- Step 1}

Basic data of material and Dimensions needed for analysis

Young's Modulus $=2.0133 \times 10^{5}$

Possion's Ratio $=0.277$

Coefficient of Friction $=0.02$

Elements type $=$ solid- 8 node 185

Diameter of Roller $=7.059 \mathrm{~mm}$

Length of Roller $=8 \mathrm{~mm}$

\section{- $\quad$ Step 2}

Meshing is created by selected mesh size 0.05 at contact surface and 0.5 at non-contact surfaces. Figure 5 


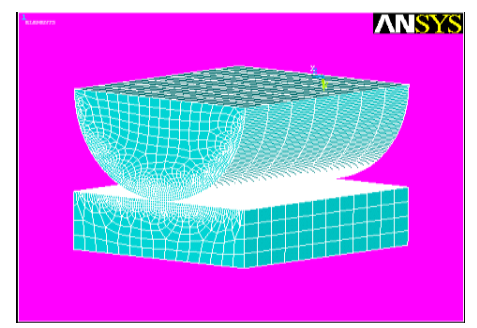

Figure 5

\section{- Step 3}

Generation of contact is done with target surface as flat surface which is equivalent to race of bearing and contact surface as roller surface. The contact pair is as shown in Figure 6.

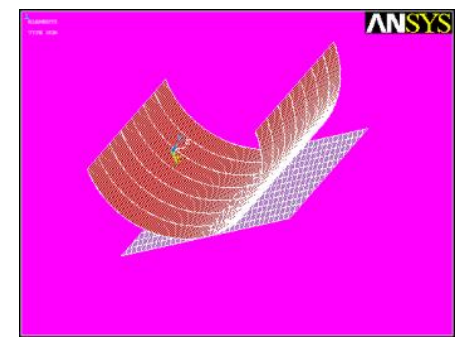

Figure 6

\section{- Step 4}

The solution is done under following prescribed conditions Figure 7:

1.) Applying all degree of freedom as zero to the race inner surface.

2.) Applying pressure $=44.270 \mathrm{~N} / \mathrm{mm}^{2}$ to the cross section area of the roller

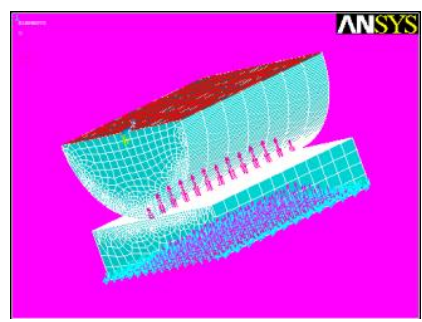

Figure 7

\section{- Step 5}

The above model analyzed in ANSYS gives the following result Von-Mises stress analysis as shown in Figure 8.

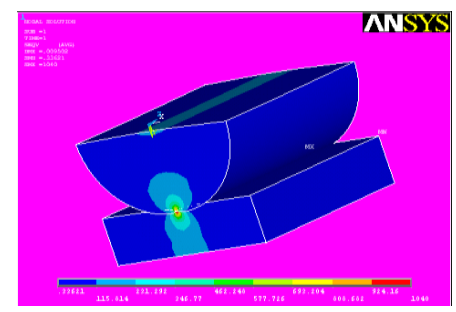

Figure 8 
Novel Double Roller Bearing Fe Analysis and Comparison with Conventional Double Row Cylindrical Roller Bearing

Contact pressure analysis as shown in Figure 9

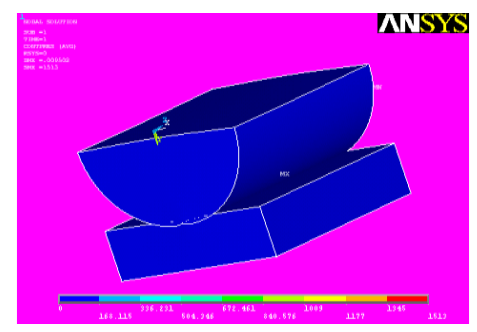

Figure 9

\subsection{Finite Element Analysis of Novel Roller [3]}

Novel roller is as shown in Figure 10 the two rollers are joined with a small diameter roller which looks like a dumbbell.

Due to graphical constraints the roller is divided into three parts two end roller and one mid roller and then the analysis in Ansys is done.

\subsubsection{Analysis of end roller.}

\section{- Step1}

Basic data of material and Dimensions needed for analysis

Young's Modulus $=2.0133 \times 10^{5}$

Possion's Ratio $=0.277$

Coefficient of Friction $=0.02$

Elements type $=$ solid-8node 185

Diameter of Roller $=7.059 \mathrm{~mm}$; Length of Roller $=8 \mathrm{~mm}$

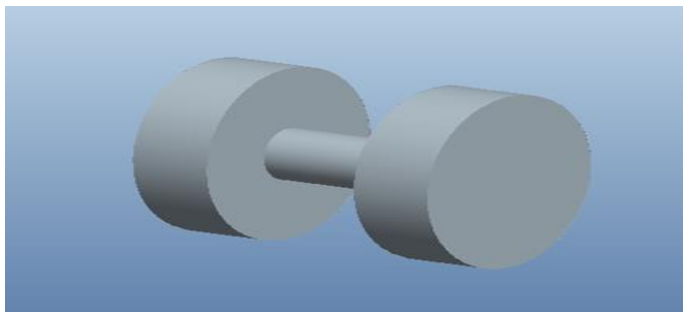

Figure 10 Novel Roller

- Step 2

Meshing is created by selected mesh size 0.05 at contact surface and 0.5 at noncontact surfaces as shown in Figure 11.

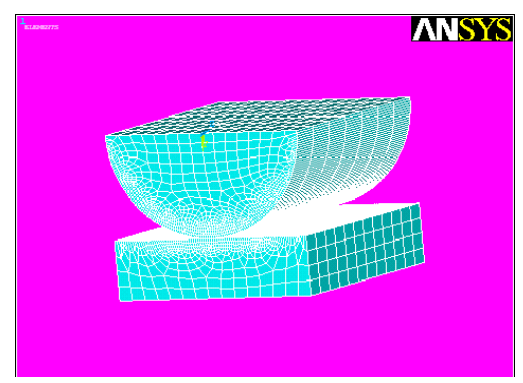

Figure 11 


\section{- Step 3}

Generation of contact is done with target surface as flat surface which is equivalent to race of bearing and contact surface as roller surface. The contact pair is as shown in Figure 12.

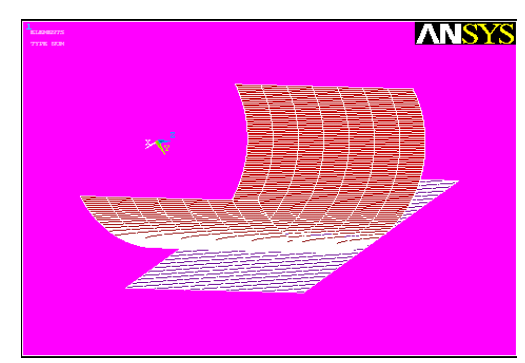

Figure 12

\section{- $\quad$ Step 4}

The solution is done under following prescribed conditions (Figure 13):

1.) Applying all degree of freedom as zero to the race inner surface.

2.) Applying pressure $=40.472 \mathrm{~N} / \mathrm{mm}^{2}$ to the cross section area of the roller.

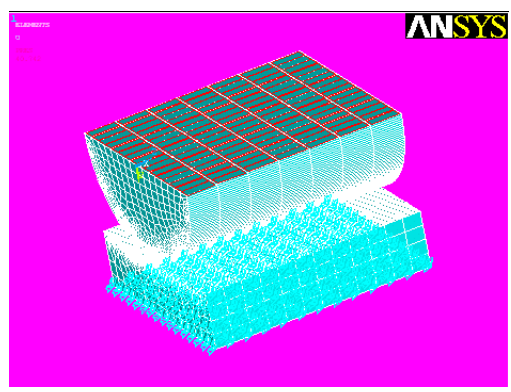

Figure 13

\section{- Step 5}

The above model analyzed in ANSYS gives the following result Von-Mises stress analysis as shown in Figure 14.

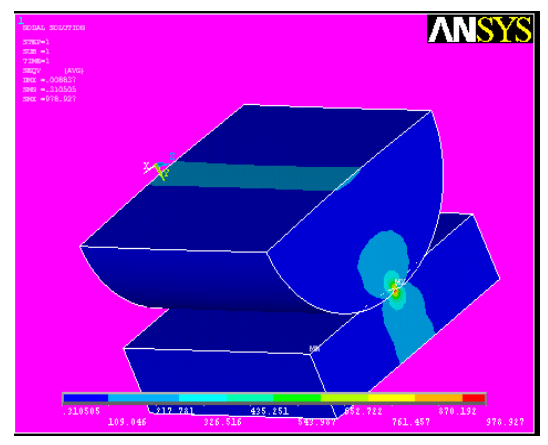

Figure 14

Contact pressure analysis as shown in Figure 15. 
Novel Double Roller Bearing Fe Analysis and Comparison with Conventional Double Row Cylindrical Roller Bearing

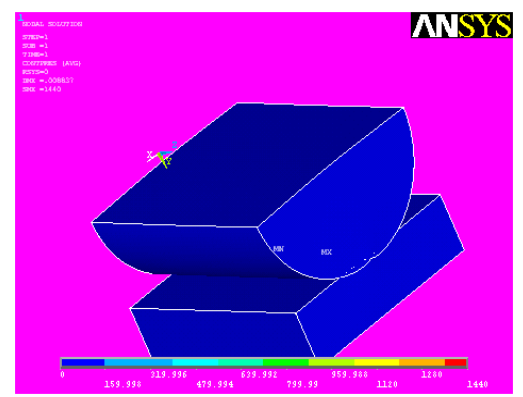

Figure 15

\subsubsection{Analysis of Mid Roller}

\section{- Step1}

Basic data of material and Dimensions needed for analysis

Young's Modulus $=2.0133 \times 10^{5}$

Possion's Ratio $=0.277$

Coefficient of Friction $=0.02$

Elements type $=$ solid-8node 185

Diameter of Roller $=3.5295 \mathrm{~mm}$

Length of Roller $=3 \mathrm{~mm}$

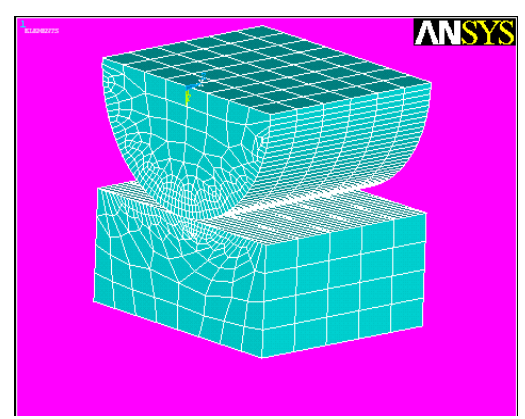

Figure 16

\section{- Step 2}

Meshing is created by selected mesh size 0.05 at contact surface and 0.5 at non-contact surfaces as shown in Figure 16.

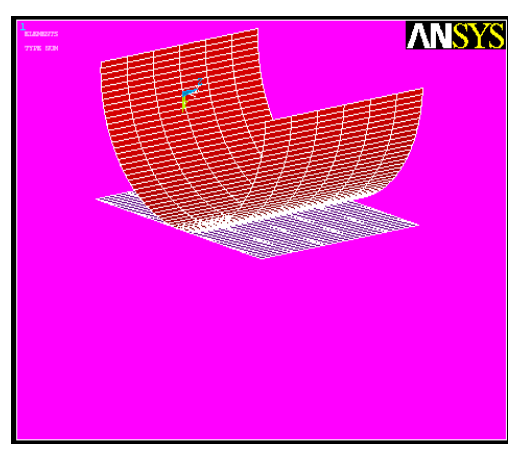

Figure 17 


\section{- Step 3}

Generation of contact is done with target surface as flat surface which is equivalent to race of bearing and contact surface as roller surface. The contact pair is as shown in Figure 17

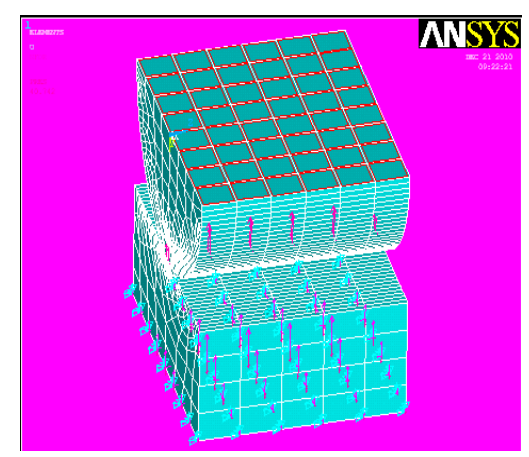

Figure 18

\section{- Step 4}

The solution is done under following prescribed conditions (Figure 18):

1.) Applying all degree of freedom as zero to the race inner surface.

2.) Applying pressure $=40.472 \mathrm{~N} / \mathrm{mm}^{2}$ to the cross section area of the roller.

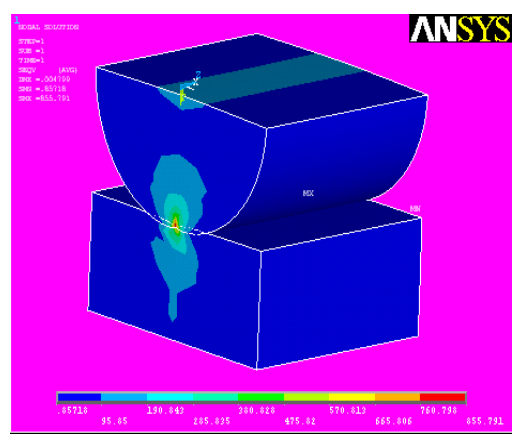

Figure 19

\section{- Step 5}

The above model analyzed in ANSYS gives the following result Von-Mises stress analysis as shown in Figure 19.

Contact pressure analysis as shown in Figure 20.

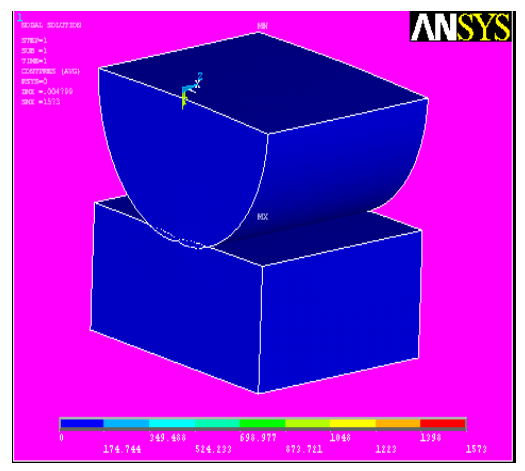

Figure 20 


\section{RESULT}

\begin{tabular}{|c|c|c|c|c|}
\hline & \multicolumn{2}{|c|}{$\begin{array}{c}\text { Double Row Cylindrical Roller } \\
\text { Bearing }\end{array}$} & \multicolumn{2}{c|}{ Novel Roller Bearing } \\
\hline & $\begin{array}{c}\text { Numerical } \\
\text { Result }\end{array}$ & $\begin{array}{c}\text { FE Analysis } \\
\text { Result }\end{array}$ & $\begin{array}{c}\text { FE Analysis } \\
\text { Of } \\
\text { END part }\end{array}$ & $\begin{array}{c}\text { FE Analysis } \\
\text { Of } \\
\text { MID part }\end{array}$ \\
\hline $\begin{array}{c}\text { Von- } \\
\text { Mises } \\
\text { Stress }\end{array}$ & 781.752 & 785.35 & 745.37 & 799.45 \\
\hline $\begin{array}{c}\text { Contact } \\
\text { Pressure }\end{array}$ & 1752.808 & 1513.00 & 1440.00 & 1573.00 \\
\hline
\end{tabular}

\section{CONCLUSION}

- As in conventional double row cylindrical bearing the load distribution is uneven, the novel design of roller eliminates that.

- In novel roller the roller are on same line of action so there is no chance of misalignment of roller.

\section{FUTURE SCOPE}

- The work can be applied to more double row cylindrical bearing for its practical application and to get more result to conclude the acceptance novel roller design for replacement of existing design of roller.

\section{REFERENCES}

[1] R.C.Patel, S.S.Sikh \& A.D.Pandya, Machine design, Baroda, Acharya Book Depot. 1958

[2] PSG College Of Technology, Design Data book, Kalaikathir Achchagam, 2007

[3] Yangang Wei, Qingyu Jiang, Yi Qinb, Raj Balendra, FE analysis of a novel roller form: a deep end-cavity roller for roller-type bearings. Journal of material's processing technology. 145 (2) 2004, 233-241.

[4] Mr. M. V. Ardeshana and Mr. N. L. Mehta, Design of Punch and Die For Taper Roller Bearing Cage For Multi Pocketing. International Journal of Design and Manufacturing Technology 2(2), 2013, pp. 367 - 372. 